\title{
Wireless RFID-Based Thermal Convection Type Inclinometer and Monitor System Design
}

\author{
Jium-Ming $\operatorname{Lin}^{1}$ and Cheng-Hung Lin ${ }^{2}$ \\ ${ }^{1}$ Dept. of Communication Engineering Chung-Hua University of Hsin-Chu, Taiwan, 30012 R.O.C. \\ ${ }^{2} \mathrm{Ph}$. D. Program in Engineering Science College of Engineering, Chung-Hua University of Hsin-Chu, Taiwan, 30012 R.O.C. \\ jmlin@chu.edu.tw, b09306014@chu.edu.tw
}

\begin{abstract}
This research proposes a wireless RFID-based thermal convection type inclinometer design, and relates more particularly to manufacture it on a flexible substrate. The key point is to integrate both an inclinometer and a wireless RFID antenna on the same substrate, such that the inclinometer is very convenient for usage. Both xenon and carbon dioxide gases were filled in the chamber, and the inner chamber shape was changed from the traditional rectangular to hemi-cylindrical one. The results by using floating and non-floating structures were studied firstly; note that the sensitivity curves by applying the non-floating structure were more linear, so it applied in this paper. To increase the sensitivity, the thermisters were stacked on some materials such as alumina nitride, copper and silicon. Three kinds of stacking height were studied, such as $1,1.5$ and $2 \mathrm{~mm}$. One can see the combinations of AlN/Xenon are always better. Besides, the xenon gas would not produce oxidization effect to the heater, it is more reliable. If the largest sensitivity is the key consideration, then $\mathrm{H} 2=1.5 \mathrm{~mm}$ is the best choice $\left(0.4^{\circ} \mathrm{C} /\right.$ Degree $)$, but the linear operating range is $45^{\circ}$. However, If the largest linear operating range is the requirement, then $\mathrm{H} 2=2 \mathrm{~mm}$ is the best one $\left(75^{\circ}\right.$ ), but the sensitivity is $0.173^{\circ} \mathrm{C} /$ Degree.

Index Terms - wireless RFID-based; thermal convection type; inclinometer; flexible substrate.
\end{abstract}

\section{Introduction}

Conventional inclinometers are manufactured on silicon wafers [1-12], and the chamber is filled with air or carbon dioxide [1-5]. The key point of this paper is to integrate both a thermal convection type inclinometer and a wireless RFID antenna on the same flexible substrate as in Fig. 1, such that it is very convenient for usage. The xenon gas is applied in the chamber instead of traditional air or carbon dioxide [6-8], because the xenon gas can increase the gas molecular weight and the sensitivity. Moreover, it would not produce oxidization effect to the heater, so it is more reliable. Besides, the inner chamber was changed from the traditional rectangular shape to hemi-cylindrical one, thus it may reduce the drag and increase the bandwidth of the inclinometer. The fabrication steps of a traditional floating type (with a cavity) for a thermal convection inclinometer are given. Both xenon and carbon dioxide gases were filled in the chamber, and the results by using floating and non-floating structures were studied firstly; note that the sensitivity curves are in nonlinear manner for the former. Besides, to increase the sensitivity performance the thermisters were stacked on some materials such as alumina nitride, copper and silicon. Three stacking height were studied such as $1,1.5$ and $2 \mathrm{~mm}$. One can see the combinations of AlN/Xenon are always better. Besides, the xenon gas would not produce oxidization effect to the heater, it is more reliable. If the largest sensitivity is the key point, then $\mathrm{H} 2=1.5 \mathrm{~mm}$ is the best choice $\left(0.4^{\circ} \mathrm{C} /\right.$ Degree $)$, but the linear operating range is $45^{\circ}$. However, If the largest linear operating range is the requirement $\left(75^{\circ}\right)$, then $\mathrm{H} 2=2 \mathrm{~mm}$ is the best one, but the sensitivity is $0.173^{\circ} \mathrm{C} /$ Degree. The paper organization is as follows: the first section is the introduction. The second one is fabrication steps. The third one is simulation and discussion. The last part is the summary.

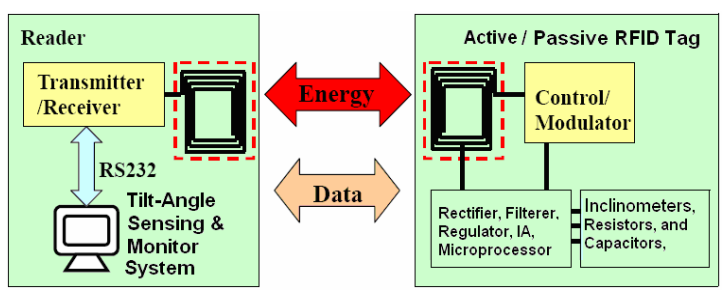

Fig. 1 Block diagram of RFID-based thermal convection inclinometer.

\section{Fabrication steps}

Step 1: Deposit $\mathrm{SiO}_{2}$ on both sides of substrate for thermal, electrical and humidity isolation. The next is to cover Photo Resist (PR) on both sides to protect $\mathrm{SiO}_{2}$. Cover a layer of SU-8 PR at the front side. Then using mask \#1 and Photolithography And Etching Processes (PAEP), a cavity is formed on the substrate. The result is in Fig. 2.

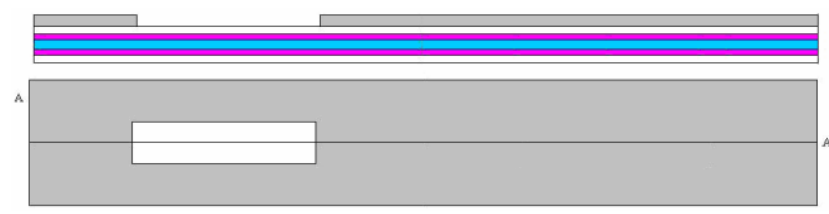

Fig. 2 Result of design Step 1.

Step 2: Deposit $\mathrm{SiO}_{2}$ on the front side of substrate as the sacrificial layer; the thickness is about one half of the SU-8 layer. The next is to cover a layer of PR on the front side. Using mask \#1 and PAEP, the PR on the cavity is remained to protect the under lying layer of $\mathrm{SiO}_{2}$. Then remove the layer of $\mathrm{SiO}_{2}$ around the cavity.

\footnotetext{
* This work is supported by National Science Council Taiwan, R.O.C. with contracts NSC-101-2622-E-216-001-CC3, 101-2221-E-216-006-MY2, and 1012221-E-216-019- to Prof. Jium-Ming Lin.
} 
Step 3: Remove PR on the cavity. Deposit a layer of alumina oxide to support the heater and temperature sensors. Cover the front side with SU-8 PR, and using mask \#2 and PAEP, only remain the PR on the cavity to protect the under lying layer of alumina oxide. The result is in Fig. 3.

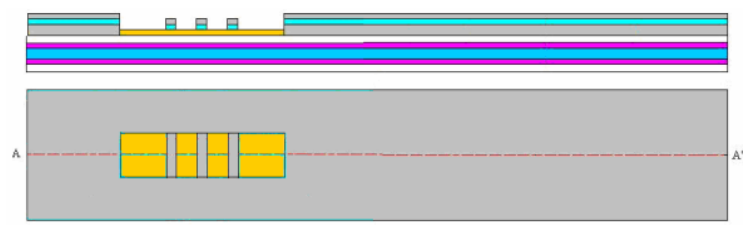

Fig. 3 Result of design Step 3.

Step 4: Deposit a layer of p-type amorphous silicon with thickness $100-250 \mu \mathrm{m}$, use an Nd-YAG laser to anneal it as a poly-silicon thermister. Then use mask \#2 and PAEP to reserve the PR on the poly-silicon thermister. Finally, use $\mathrm{KOH}$ solution or RIE process to remove the layers of polysilicon without PR protection. After remove the PR, the result is as shown in Fig. 4.

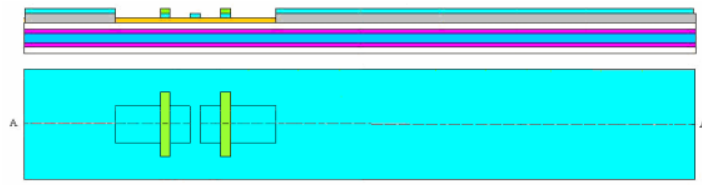

Fig. 4 Result of design Step 4.

Step 5: Deposit layers of $\mathrm{Cr}$ and $\mathrm{Ni}$ as heater, RFID antenna, and the conductors connected to the power supply. Then use mask \#4 and PAEP to reserve the PR on the heater, RFID antenna, and the conductors connected to the power supply. Finally, use sulfuric acid solution or RIE process to remove the layers of $\mathrm{Cr}$ and $\mathrm{Ni}$ without $\mathrm{PR}$ protection. After remove the PR, the result is as shown in Fig. 5.

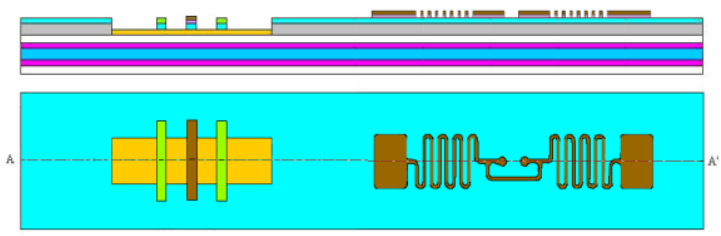

Fig. 5 Result of design Step 5.

Step 6: Use mask \#5 and PAEP to reserve the PR on the heater, flash a layer of gold on Ni by electroless-plating. Thus the conductivity of the RFID antenna, and the conductors connected to the power supply can be very good. Besides, the soldering process on the pads for packaging would also be increased. The result is as shown in Fig. 6.

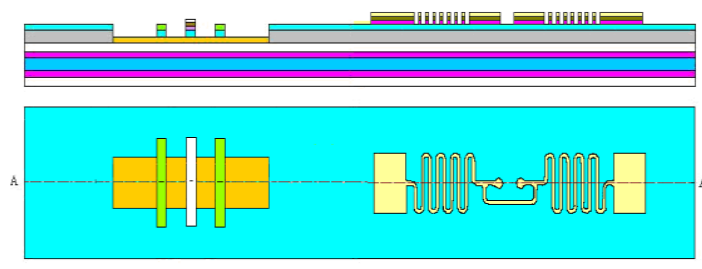

Fig. 6 Result of design Step 6.
Step 7: Cover PR on the front side. Use mask \#2 and PAEP to make the silicon dioxide layer uncovered by the PR at the cavity. Remove the dioxide layer, then the heater and the thermisters can be released and suspended over the cavity, the result is as shown in Fig.7.

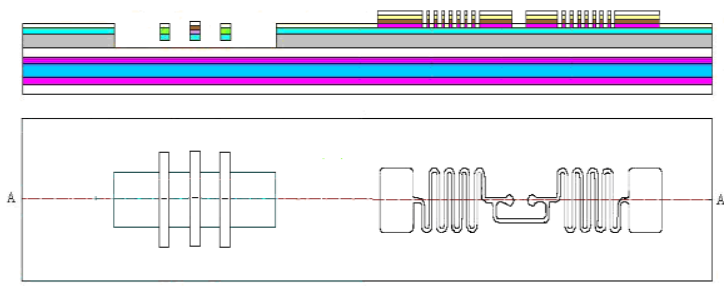

Fig. 7 Result of design Step 7.

Step 8: Remove PR, and screen print plastic or polymer material around the inclinometer as dam bar, then put a cap on the dam bar and curing, before sealing it one can fill it with xenon or the previous carbon dioxide gas. Finally, the chip with metal bump is flip chip bonded to the RFID feed terminal by thermal compression method, then the result is in Fig. 8

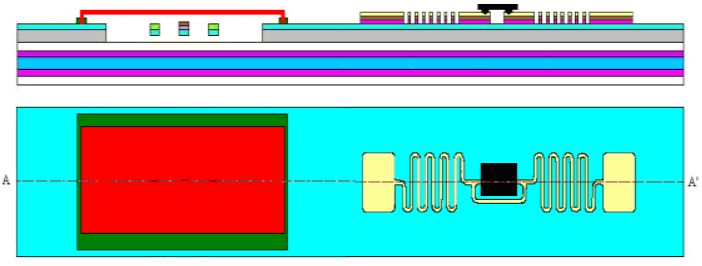

Fig. 8 Result of design Step 8.

Step 9: Put a socket and/or a spring to fix a battery on the substrate, the result is as shown in Fig.9, in which a full differential bridge sensor circuit is applied.

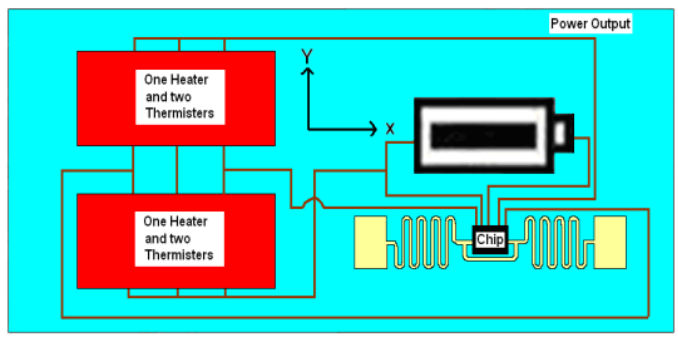

Fig.9 Result of design Step 9.

\section{Simulation and Discussions}

In this section we use ESI-CFD ${ }^{+}$software for simulation. Let the length and the floating height (H1) of thermisters and heater are $9 \mathrm{~mm}$ and $1 \mathrm{~mm}$, respectively. The geometry of the inclinometer of floating type with a cavity is as shown in Fig. 10 (a), in which $\mathrm{W} 1=0.5 \mathrm{~mm}, \mathrm{~W} 2=1 \mathrm{~mm}, \mathrm{~S}=1.25 \mathrm{~mm}$ and $\mathrm{H}=8.7 \mathrm{~mm}$. Besides, the temperature of the package boundaries and the heater are set as 300 and $400^{\circ} \mathrm{K}$, respectively. The chamber is filled with xenon or carbon dioxide gas. Then the temperature differences at the center points of thermisters versus the tilt angles are as shown in Fig. 11. Note the sensitivity curves are in nonlinear manner by using xenon and 
carbon dioxide gases. Thus the floating structure is not good; and we will apply the nonfloating type as shown in Fig. 10(b) (without making a cavity in Steps 1-3 and 7) in this paper the next. Note to increase the sensitivity performance, the thermisters are stacked on a material as shown in Fig. 10(b), in which $\mathrm{W} 1=0.5 \mathrm{~mm}, \mathrm{~W} 3=0.5 \mathrm{~mm}, \mathrm{~S}=1.25 \mathrm{~mm}$ and $\mathrm{H}=9 \mathrm{~mm}$. The stacking material can be anyone of alumina nitride, copper and silicon. The thermal conductivity and the specific heat of these materials are listed in TABLE I. Besides, three values of $\mathrm{H} 2$, e.g. $1 \mathrm{~mm}, 1.5 \mathrm{~mm}$, and $2 \mathrm{~mm}$, are also tested for comparison.
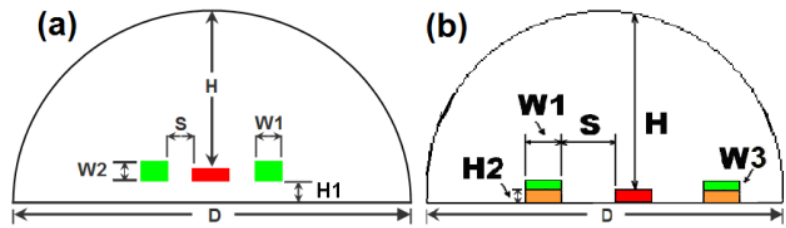

Fig.10 Geometry of inclinometers. (a) Floating type with a cavity. (b) Nonfloating type without a cavity.

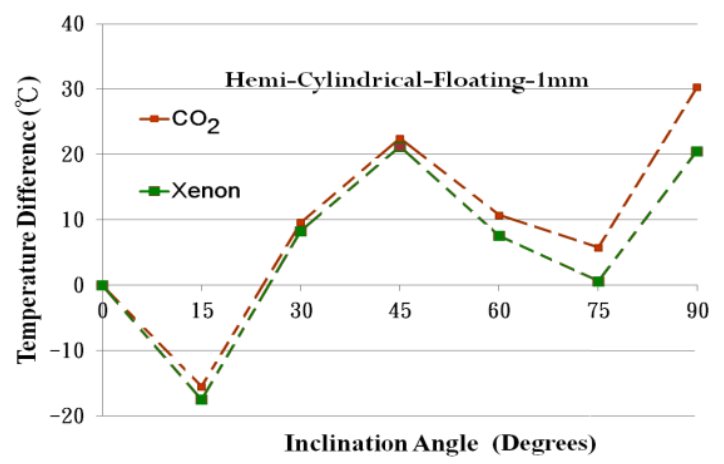

Fig.11 Sensitivity curves of floating type inclinometer with a cavity.

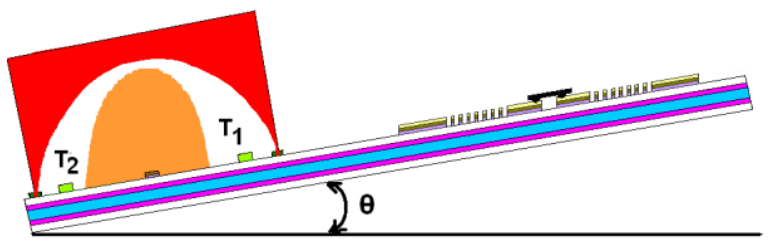

Fig.12 Nonfloating type inclinometer by tilting an angle $\theta$.

TABLE I Thermal Conductivity and Specific Heat of Stacking Materials.

\begin{tabular}{|c|c|c|}
\hline \multirow{2}{*}{ Stacking Materials } & \multicolumn{2}{|c|}{ Materials } \\
\cline { 2 - 3 } & Thermal Conductivity & Specific Heat \\
\hline Aluminum nitride & 160 & 740 \\
\hline Copper & 385 & 385 \\
\hline Silicon & 124 & 702 \\
\hline
\end{tabular}

The sensitivity curves without a cavity by using $\mathrm{CO}_{2}$ and $\mathrm{Xe}$ gases for various stacking materials $(\mathrm{H} 2=1 \mathrm{~mm})$ are as shown in Figs. 13(a) and (b). Note the case by using AlN and
Xe gas is better as shown in Fig.14, the linear operating range and sensitivity are $45^{\circ}$ and $0.267^{\circ} \mathrm{C} /$ Degree, respectively.
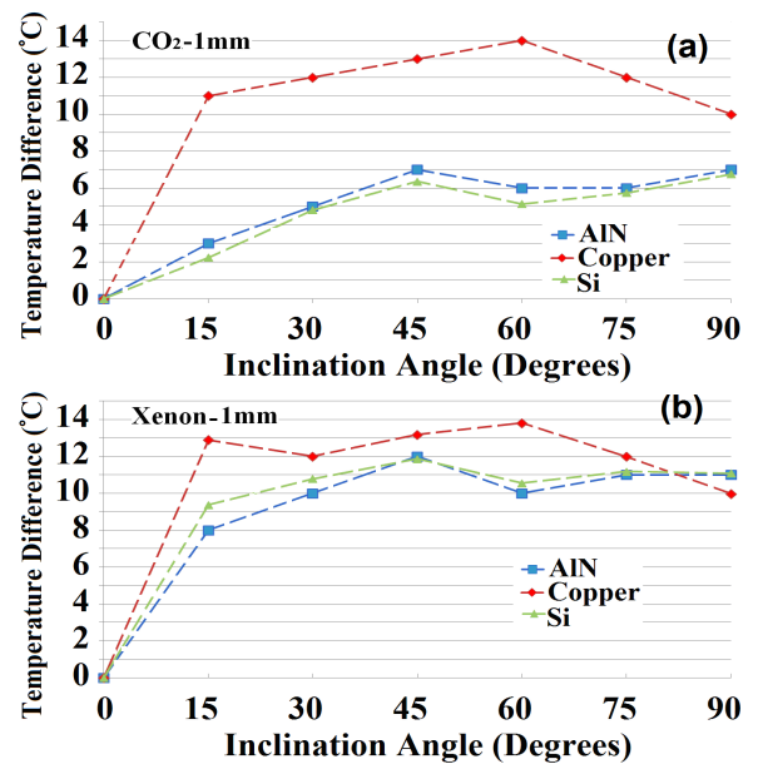

Fig.13 Sensitivity curves by using (a) $\mathrm{CO}_{2}$ and (b) $\mathrm{Xe}(\mathrm{H} 2=1 \mathrm{~mm})$.

The results for $\mathrm{H}_{2}=1.5 \mathrm{~mm}$ and $2 \mathrm{~mm}$ by using $\mathrm{CO}_{2}$ and xenon gases are respectively as shown in Figs. 15 and 16. Also note the case for $\mathrm{H} 2=1.5 \mathrm{~mm}$ by using AlN and Xe is better by comparing Figs. 14(a) and (b), the linear operating range is still $45^{\circ}$, but the sensitivity is increased to $0.4^{\circ} \mathrm{C} /$ Degree. Besides, if $\mathrm{H} 2=2 \mathrm{~mm}$ and comparing Figs. 15 (a) and (b), note that the better case is in Fig. 15(b) by applying AlN and Xe, the linear operating range is increased to $75^{\circ}$, but the sensitivity is reduced to $0.173^{\circ} \mathrm{C} /$ Degree.
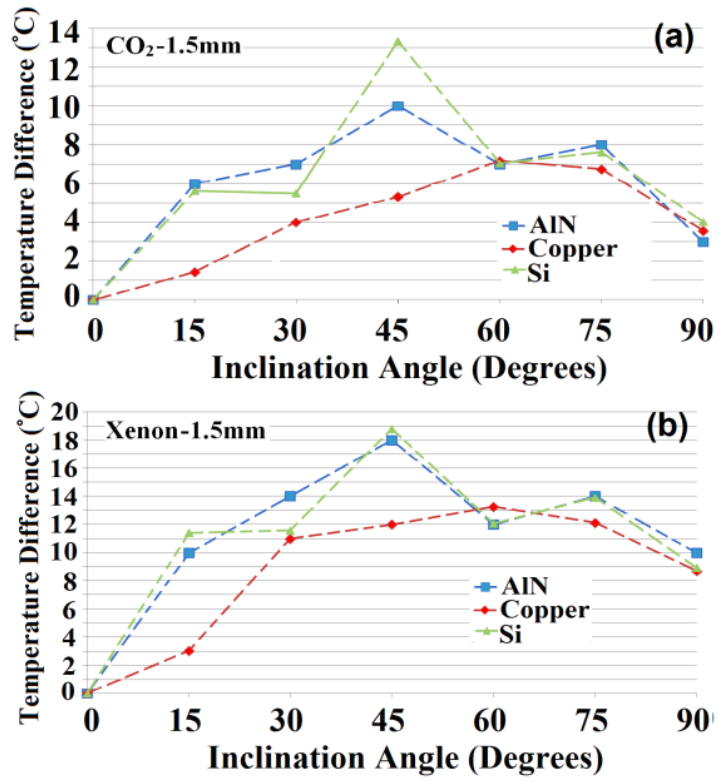

Fig.14 Sensitivity curves by using (a) $\mathrm{CO}_{2}$ and (b) $\mathrm{Xe}(\mathrm{H} 2=1.5 \mathrm{~mm})$. 

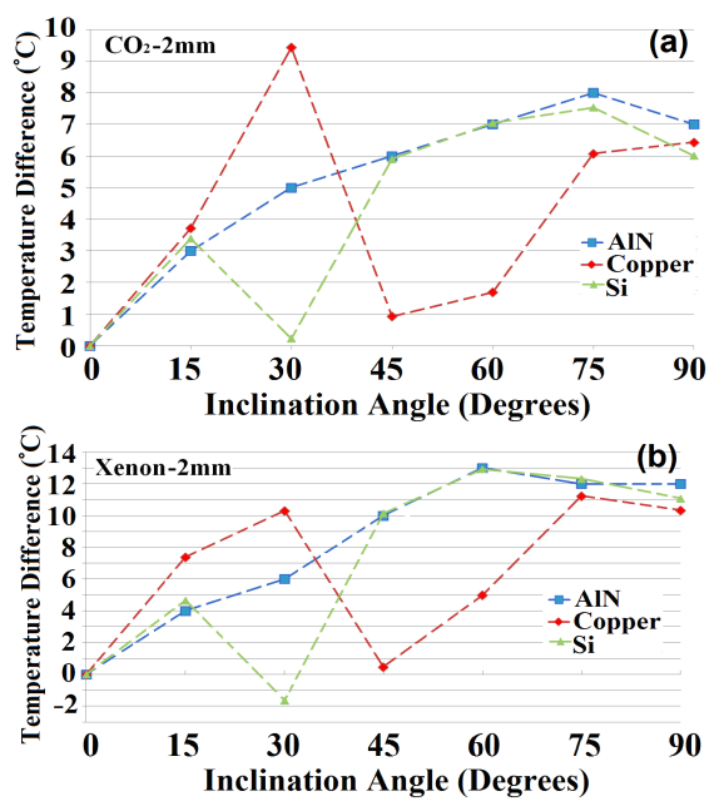

Fig.15 Sensitivity curves by using (a) $\mathrm{CO}_{2}$ and (b) $\mathrm{Xe}(\mathrm{H} 2=2 \mathrm{~mm})$.

Finally, the better cases of linear operating ranges and sensitivities, with various stacking material/gas combinations, are listed in TABLE II; the combinations of AlN/Xenon are always better. If the largest sensitivity is the key consideration, then $\mathrm{H} 2=1.5 \mathrm{~mm}$ is the best choice $\left(0.4^{\circ} \mathrm{C} /\right.$ Degree $)$, but the linear operating range is $45^{\circ}$. However, If the largest linear operating range is the requirement, then $\mathrm{H} 2=2 \mathrm{~mm}$ is the best one $\left(75^{\circ}\right)$, but the sensitivity is $0.173^{\circ} \mathrm{C} /$ Degree.

\section{Conclusion}

This research proposes a wireless RFID-based thermal convection type inclinometer design, and relates more particularly on the processes to manufacture it on a flexible substrate. The novel idea is to integrate both an inclinometer and a wireless RFID antenna on the same substrate, such that it is a wireless inclinometer and very convenient for usage.

Both xenon and carbon dioxide gases were filled in the chamber, and the inner shape of the chamber was changed as hemi-cylindrical instead of the traditional rectangular ones. The results by using floating and non-floating structures were studied; note that the sensitivity curves are in nonlinear manner for the former. So the non-floating structure was applied in this paper. To increase the sensitivity, the thermisters were stacked on some materials such as alumina nitride, copper and silicon. Three kinds of stacking height were studied such as $1,1.5$ and $2 \mathrm{~mm}$. Note that the combinations of AlN/Xenon are always better. Besides, the xenon gas would not produce oxidization effect to the heater, it is more reliable. If the largest sensitivity is the key point of consideration, then $\mathrm{H} 2=1.5 \mathrm{~mm}$ is the best choice $\left(0.4^{\circ}\right.$ $\mathrm{C} /$ Degree), but the linear operating range is $45^{\circ}$. However, if the largest linear operating range is the requirement, then $\mathrm{H} 2=2 \mathrm{~mm}$ is the best one $\left(75^{\circ}\right)$, but the sensitivity is $0.173^{\circ}$ $\mathrm{C} /$ Degree.
TABLE II Better Cases of Stacking Material/ Gas Combinations, Linear Operating Ranges and Sensitivities.

\begin{tabular}{|l|c|c|c|}
\hline $\begin{array}{c}\text { Heights of Stacking } \\
\text { Material (H2) }\end{array}$ & $\begin{array}{c}\text { Stacking } \\
\text { Material/ Gas } \\
\text { Combinations }\end{array}$ & $\begin{array}{c}\text { Linear Operating } \\
\text { Range (Degree) }\end{array}$ & $\begin{array}{c}\text { Sensitivity } \\
\left({ }^{\circ} \text { C/Degree) }\right.\end{array}$ \\
\hline $1 \mathrm{~mm}$ & AlN/Xenon & 45 & 0.267 \\
\hline $1.5 \mathrm{~mm}$ & AlN/Xenon & 45 & 0.4 \\
\hline $2 \mathrm{~mm}$ & AlN/Xenon & 75 & 0.173 \\
\hline
\end{tabular}

\section{Acknowledgment}

This research was supported by National Science Council Taiwan, R.O.C. with contract NSC-101-2622-E-216-001-CC3, 101-2221-E-216-006-MY2, and 101-2221-E-216-019-. Besides, we are grateful to the National Center for Highperformance Computing (NCHC) for computer time and facilities of ESI-CFD ${ }^{+}$software package.

\section{References}

[1] S. Billata, H. Glosch, M Kunze, F. Hedrich, J. Frech, J. Auber, H. Sandmaier, W. Wimmer, and W. Lang, "Micromachined inclinometer with high sensitivity and very good stability," Sensors and Actuators A: Physical, vol .97-98, no.1, pp. 125-130, April 2002.

[2] S. Billat, H. Glosch, M. Kunze, F. Hedrich, J. Frech, J. Auber, H. Sandmaier, W. Wimmer, and W. Lang, "Convection based micromachined inclinometer using SOI technology," MEMS 01, pp. 159-161, January 2001.

[3] M.A. Adams, P. Dolan, C. Marx, and W.C. Hutton, "An electronic inclinometer technique for measuring lumbar curvature," Clinical Biomechanics, vol. 1, no. 3, pp. 130-134, August 1986.

[4] O. Frazão, R. Falate, J.L. Fabris, J.L. Santos, L.A. Ferreira, and F. M. Araújo, "Optical inclinometer based on a single long-period fiber grating combined with a fused taper," Optics Letters, vol. 31, no. 20, pp. 29602962, October 2006.

[5] A.G. Butler, D.G. Green, and R.E. Nagle, "Inclinometer," US patent US 4912662 A, March 1990.

[6] Y. Zhao and YY. Cai, "Temperature-gradient cancellation technique and device," US Patent US 7,862,229 B2 January 2011.

[7] B. Alain, R. Alain, V. Bernard, G. Alain, "Thermal accelerometer with reduced sensitivity to an external magnetic field," European Patent EP1550874 B1, June 2010.

[8] G. Daia, M. Li, X.P. He, L.M. Du, B.B. Shao, and W. Su, "Thermal drift analysis using a multiphysics model of bulk silicon MEMS capacitive accelerometer," Sensors and Actuators A: Physical, vol. 172, no. 2,pp. 369-378, December 2011.

[9] A.H. Ma, A.M. Leung, "Three-axis thermal accelerometer based on buckled cantilever microstructure," IEEE Sensors, pp. 1492-1495, October 2008.

[10] J. Courteaud, P. Combette, N. Crespy, G. Cathebras, A. Giani, "Thermal simulation and experimental results of a micromachined thermal inclinometer," Sensors and Actuators A: Physical, vol. 141, no. 2, pp. 307-313, February 2008.

[11] A.M. Leung, J. Jones, E. Czyzewska, J. Chen, and B. Woods, "Micromachined accelerometer based on convection heat transfer," MEMS 98, pp. 627-630, January 1998.

[12] V. Milanovic, E. Bowen, Nim Tea, J. Suehle, B.Payne, M. Zaghloul, and M. Gaitan, "Convection based accelerometer and tilt sensor implemented in standard CMOS," MEMS 98, pp. 487-490, November 1998. 